\title{
Astronomers bargain for use of 'sacred' site
}

Tony Reichhardt, Washington

Construction of a NASA-funded telescope array on Mauna Kea in Hawaii has been held up by wrangling between astronomers and Hawaiians over the use of the sacred mountain, already home to some of the world's most powerful telescopes.

The delay to the $\$ 50$ million Keck Interferometer - now stretching into its seventh month - is being watched closely by astronomers, who fear that one of their premier viewing sites is becoming increasingly mired in Hawaii's cultural politics.

The Mauna Kea site has been prized by astronomers since the first telescope was built there in 1968. Today a dozen observatories - operated by US, European, Canadian and Japanese astronomers - dot the stark landscape near the summit.

But in recent years a growing Hawaiian movement has objected to the telescopes on the grounds that they desecrate the ancient volcano, according to local tradition the home of the snow goddess. Each new project has been hotly contested, and some Hawaiian groups have even called for existing telescopes to be pulled down.

"The astronomy community was unprepared for this backlash," admits William Smith, president of the Association of Universities for Research in Astronomy (AURA), which manages the 8-metre Gemini telescope on Mauna Kea.

NASA began work in 1997 to link the two existing 10-metre Keck telescopes together as an optical interferometer to improve their ability to see fine detail, and to search for planets around other stars. But this means that at least four small 'outrigger' telescopes must be built near the large Keck domes.

A master plan for the Mauna Kea Science Reserve, completed last summer after two years of intense discussion and compromise among scientists, environmentalists and native Hawaiian groups, identified the interferometer as one of two approved expansion projects on the mountain.

Construction of the outriggers was to have begun in October, with a view to having the interferometer in use by next spring. But NASA is still embroiled in a lengthy process to ensure compliance with federal environmental and historic preservation laws - and ultimately to protect itself against lawsuits from groups opposed to astronomy on the mountain. Construction permits have not yet been granted for the outriggers.

In December, NASA published a draft environmental assessment of the project, which includes, among other provisions, a mitigation strategy for the wekiu bug (Nysius wekiuicola) that lives on Mauna Kea and is a candidate for protection under the Endangered Species Act. NASA hopes the assessment

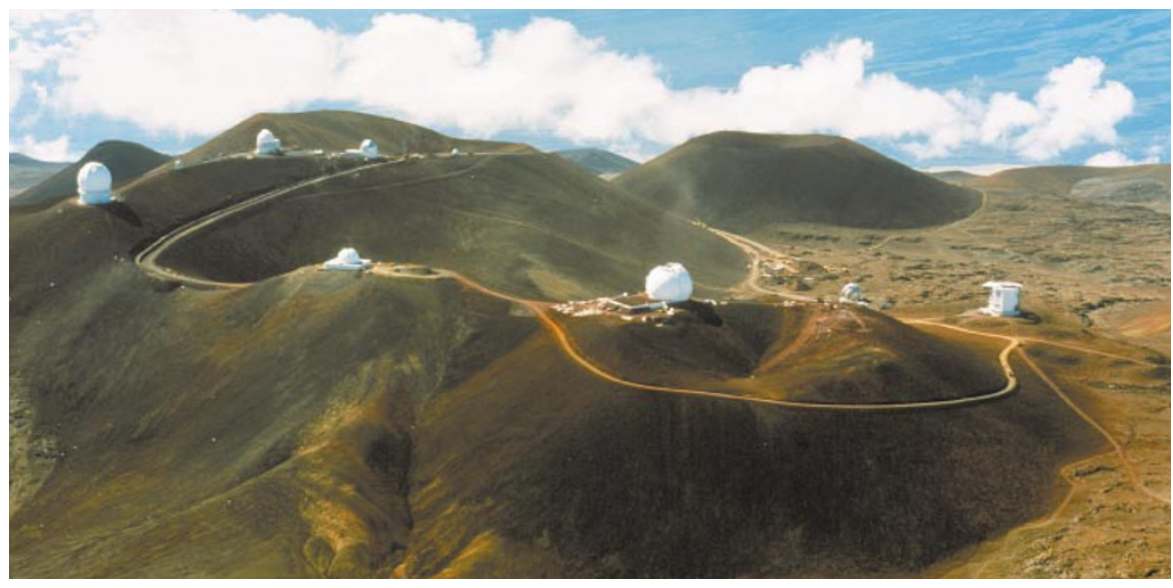

Heavenly view: but planned new facilities have sparked environmental and cultural opposition.

will satisfy environmental concerns: a more detailed environmental impact statement would add significantly to costs and delays.

Another consideration is the National Historic Preservation Act, which protects sites of cultural interest. In 1999, Hawaii's office of historic preservation concluded that the mountain meets the criteria for listing as a historic site. NASA has been discussing preservation and outreach measures with historic and cultural groups ever since.

Among the possibilities being discussed are having an archaeologist present while the outriggers are built, contributing to native Hawaiian schools, educating astronomers about the sacred traditions of Mauna Kea, and increasing the number of native-born Hawaiians working at the observatories.

"We want to do what is right," says John
Lee, programme manager for the Keck Interferometer at NASA headquarters in Washington. "We don't want to poison the well" for astronomy on the mountain, he says. Most observatories on Mauna Kea will eventually need to modernize their telescopes.

Three new projects are also included in the master plan, including the ambitious Giant Segmented-Mirror Telescope, which is still in the conceptual stage, but at 30 metres diameter would be by far the largest optical telescope ever built.

NASA managers are aware of the pressure to resolve the dispute. Astronomers "see themselves losing their best Northern Hemisphere site", says Anne Kinney, science director for the agency's Origins programme. Further delays "would hold up every single project on the mountain".

\section{Weapons lab seeks Mexican link}

\section{Rex Dalton, San Diego}

Sandia National Laboratory, a nuclear weapons lab in New Mexico, has launched plans for an applied-technology laboratory on the border between the United States and Mexico.

Scientists and engineers at the Bi-National Sustainability Laboratory would work on developing technologies to make new products in the fields of energy, water, air quality, health care and information services.

The new lab would be sited in the border cities of Santa Teresa, New Mexico, and San Jeronimo, Chihuahua, Mexico. These are part of a jointly planned development area that includes a border crossing.

The lab is being promoted by Sandia's Advanced Concepts Group, which pursues new research ideas. "The idea is a mix of a scientific incubator, think-tank and technology start-up," says Sandia engineer Vipin Gupta, a member of the group. Sandia officials hope the new lab will be funded equally by the US and Mexican governments, and be staffed by scientists from both countries. Sandia planners were in Mexico last week looking for an agency there to be the primary partner. The United States-Mexico Foundation for Science, a think-tank based in Mexico City, Mexico, is helping with project planning.

The cost of building and operating the lab has yet to be determined, although Sandia officials have employed an architect to create a model of the facility.

The location and focus of the lab are the idea of Sandia engineer Gerry Yonas. "We see this as a tremendous opportunity," he says. "But if we are going to make this concept a reality, we need a full partner in Mexico." 